\title{
VIDA E MORTE DO MARACANÃ: A BATALHA DO ESTÁDIO EM DOIS ATOS
}

Life and death of Maracanã: the battle of the stadium in two acts

Vida y muerte del Maracanã: la batalla del estadio en dos actos

\author{
ERICK SILVA OMENA DE MELO ${ }^{\text {I* }}$
}

GABRIEL DA SILVA VIDAL CID ${ }^{I * *}$

DOI: http://dx.doi.org/10.1590/S2178-14942019000300008

\footnotetext{
' Universidade Federal do Rio de Janeiro (UFRJ), Rio de Janeiro - RJ, Brasil.

* Pesquisador bolsista da FAPERJ (Pós-doutorado nota 10) no Programa de Pós-graduação em Planejamento Urbano e Regional do Instituto de Pesquisa e Planejamento Urbano e Regional (IPPUR) da Universidade Federal do Rio de Janeiro (UFRJ), (erickomena@gmail.com), ORCID iD: https://orcid.org/0000-0003-2890-9446.

"Universidade do Estado do Rio de Janeiro (UERJ), Rio de Janeiro - RJ, Brasil.

* Pesquisador bolsista de Pós-doutorado do CNPq, no Programa de Pós-graduação em Ciências Sociais (PPCIS), da Universidade do Estado do Rio de Janeiro (UERJ) (gabrielsvcid@gmail.com);

ORCID iD: https://orcid.org/0000-0003-0479-041X
}

Artigo recebido em 01 de julho de 2019 e aceito para publicação em 08 de outubro de 2019. 


\section{RESUMO}

0 artigo resgata os principais embates acerca das ressignificações do estádio do Maracanã, cujos resultados influenciaram decisivamente as decisões sobre o destino desse importante ícone esportivo. Destacam-se dois momentos históricos fundamentais: o planejamento (1946-1950) e o período de reformas (1999-2013), em contraponto com o processo de tombamento. Com base em acervo de jornais que reportam o processo desenrolado no primeiro momento e em arquivos institucionais do Instituto do Patrimônio Histórico e Artístico Nacional (Iphan) que registram a memória sobre o segundo, os autores identificam o caráter popular, público e monumental do Maracanã como elemento central de sua identidade em risco.

PALAVRAS-CHAVE: Maracanã; Futebol, Patrimônio histórico; Cultura popular; Copa do Mundo.

\section{ABSTRACT}

The paper recovers the main struggles over the resignification of the Maracanã stadium, which decisively influenced decisions on the destiny of this sports icon. The focus relies on two major historical moments: the planning period (1946-1950) and the refurbishment period (1999-2013), marked by controversies related to lifting of heritage protection. Newspaper archives are utilized to analyse the former, whereas institutional archives of Institute of National Historical and Artistic Heritage (IPHAN) are used for analysing the latter. The authors recognise the popular, public and monumental character of Maracanã as the core element comprising its identity.

KEYwORDS: Maracanã; Football; Heritage, Popular culture; World Cup.

\section{RESUMEN}

El artículo rescata los principales embates acerca de las resignificaciones del estadio del Maracanã, cuyos resultados influenciaron decisivamente las decisiones acerca del destino dado a este importante ícono deportivo. Se destacan dos momentos históricos fundamentales: la planificación (1946-1950) y el período de implementación de reformas (1999-2013), en su contrapunto con el proceso de protección histórico-patrimonial. Utilizando acervo de periódicos que reportan el proceso desenrollado en el primer momento y archivos institucionales del Instituto de Patrimonio Histórico y Artístico Nacional (Iphan) que registran la memoria existente sobre el segundo, los autores identifican el carácter popular, público y monumental del Maracanã como elemento central de su identidad en riesgo.

PALABRAS ClAVE: Maracanã; Fútbol; Patrimonio; Cultura popular; Mundial. 


\section{INTRODUÇÃO}

$\mathrm{N}$ o dia 25 de julho de 1946, em Luxemburgo, o Brasil foi escolhido como país sede da quarta Copa do Mundo pela Federação Internacional de Futebol (Fifa). A realização da competição em 1950 marcou profundamente o imaginário dos brasileiros por várias décadas, impactados pela derrota da Seleção no último jogo. A vitória uruguaia e a frustração coletiva já foram contadas, recontadas e analisadas inúmeras vezes. Muito menos explorada, entretanto, foi a trajetória do palco daquela "tragédia nacional", cujo desenrolar apresenta similar dramaticidade.

Com o objetivo de dar conta dos principais pontos de inflexão dessa trajetória, o artigo está dividido em duas grandes seções. Na primeira, exploramos a história da construção do Maracanã, como ficou popularmente conhecido o Estádio Mario Filho. 0 foco está nas narrativas de atores-chave na disputa em torno do projeto a ser construído. Tais discursos se distinguem nas suas diferentes concepções de esporte, cidade e sociedade, que influenciariam significativamente esse emblemático cartão-postal do Rio de Janeiro.

Na segunda seção, são analisadas as tentativas de desconstrução material e simbólica do estádio, iniciadas no fim do século XX e associadas à preparação da cidade para o que ficou conhecido como megaeventos, bem como as resistências articuladas sobretudo por meio do processo de tombamento junto ao Instituto do Patrimônio Histórico e Artístico Nacional (Iphan). 1

\section{PRIMEIRO ATO: DISPUTAS SOBRE UM NOVO ESTÁDIO PARA A COPA DO MUNDO (1946-1950)}

P rimeiramente anunciada em 1938, a candidatura brasileira a país sede da Copa do Mundo logrou sucesso em 1946, com o evento sendo reprogramado de 1942 para 1949 em função da Segunda Guerra Mundial (1939-1945) e, posteriormente, para 1950.2 Duas razões, de modo geral, são elencadas para a escolha da Fifa. A principal e mais difundida se resume à impossibilidade de os países europeus, destruídos pela guerra, proverem a infraestrutura necessária. Outro motivo consiste na necessidade geopolítica de retornar a Copa do Mundo para um país sul-americano (Franzini, 2010).

Após capitanear a chamada "Revolução de 30", presidir o país durante o período que a sucedeu e comandar a instauração do regime ditatorial denominado Estado Novo, Getúlio Vargas foi destituído em outubro de 1945, quando ocorreram novas eleições gerais. Poucos meses antes de ser anunciado como sede, o país vivia a reabertura democrática, que exigia um 
reposicionamento das forças que comandavam o Estado brasileiro, em especial no que se refere à maneira como lidavam com os setores populares. Tal reposicionamento já se configurava, ainda que de forma tímida, no fim do Estado Novo, por meio de importantes concessões às lutas das classes populares, como a Consolidação das Leis do Trabalho e a promulgação da Lei Orgânica da Previdência Social. Além disso, as práticas de propaganda oficial, que buscavam ampliar consensos em torno das políticas públicas implementadas, também se fortaleceram, em especial com a intensificada utilização da imprensa escrita e do rádio (Aggio, Barbosa e Coelho, 2002).

Nesse contexto, o futebol, como fenômeno de massas emergente, ganhou particular importância. ${ }^{3}$ Nas décadas de 1930 e 1940, o esporte recebeu um impulso decisivo para sua popularização graças à combinação de vários fatores, como rápido crescimento demográfico, formando uma estrutura etária populacional extremamente jovem (Alves e Bruno, 2006); baixíssima exigência de equipamentos para sua prática; popularização em nível nacional dos campeonatos por meio das transmissões de rádio; e possibilidades de ascensão social para a população jovem, pobre e negra das grandes cidades (Pereira, 2000; Rodrigues Filho, 2003; Souza, 2008).

0 crescente interesse pelo futebol e as possibilidades abertas por ele como mais um veículo de estreitamento de relações entre representantes do poder público e a população trabalhadora urbana despertava particular interesse no alto escalão de governo desde o fim da década de 1930 (Pereira, 2000). Não por acaso, a assinatura da CLT, em 1943, se deu no Estádio de São Januário. Portanto, a realização do torneio mundial e a possibilidade de construir o "maior estádio do mundo" no Rio de Janeiro eram de grande interesse tanto de Eurico Gaspar Dutra, ex-ministro da guerra de Vargas e presidente eleito em 1945, quanto das autoridades locais, configurando-se como oportunidade de popularização de seus programas.

Não tardou para que, pouco tempo após o anúncio do Brasil como sede da Copa do Mundo, houvesse grande movimentação em torno das decisões sobre a organização do evento e da construção de um estádio.

Os agentes protagonistas das disputas pela definição do projeto se dividiam em dois grandes campos. 0 primeiro era liderado por Mario Filho, proprietário, editor e cronista esportivo do Jornal dos Sports, com a contribuição de importantes personalidades da vida pública carioca e nacional, como Ary Barroso — radialista, cronista esportivo, advogado e vereador pela União Democrática Nacional (UDN) -, Vargas Neto — deputado pelo Partido Trabalhista Brasileiro (PTB) e cronista do Jornal dos Sports, além de sobrinho de Getúlio Vargas — e José Lins do Rego - escritor e cronista do Jornal dos Sports. Esse grupo tinha conexões estreitas 
com dirigentes de clubes e entidades esportivas nacionais, como a Confederação Brasileira de Desportos (CBD), além de artistas e intelectuais.

Já o campo rival tinha como figura central Carlos Lacerda - vereador pela UDN e cronista do Correio da Manhã -, além de Diocesano Ferreira Gomes — dirigente do Clube de Regatas do Flamengo e cronista do Correio da Manhã — e Tito Lívio Santana — vereador pela UDN. Suas iniciativas eram apoiadas por grandes empresários, como Fausto Matarazzo, cuja família era proprietária de um dos maiores complexos industriais do país, e profissionais liberais, como o engenheiro Antonio Laviola.

Como se pode notar, tratava-se de uma disputa entre setores das elites econômicas, políticas e culturais do país que, por suas posições privilegiadas, usufruíam de acesso à esfera pública e aos mecanismos de conformação de seu conteúdo. Apresentamos a seguir os principais objetos de discordância, com base em levantamento de números do Jornal dos Sports e do Correio da Manhã, entre julho de 1946 e junho de 1950. ${ }^{4}$ A escolha desses periódicos se deu porque ambos protagonizaram os embates à época, dedicando relevante espaço ao tema (Melo, 2011). ${ }^{5}$

\section{ONDE CONSTRUIR O NOVO ESTÁDIO?}

pós esporádicas discussões sobre a necessidade de um novo estádio no Distrito Fede-
ral, ${ }^{6}$ os embates seguiram a questões mais contenciosas. Uma das principais consistia na decisão sobre a localização.

0 grupo liderado por Mario Filho defendia a construção no bairro do Maracanã, mais precisamente no terreno do antigo Derby Clube, onde aconteciam corridas de cavalo desde 0 fim do século XIX. O local já vinha sendo cogitado para um novo estádio, independentemente da realização da Copa do Mundo. O Jornal dos Sports defendeu essa posição utilizando os seguintes argumentos: facilidade de aquisição do terreno por parte da prefeitura, cujo trâmite junto ao governo federal e ao Derby Clube já havia iniciado:7 centralidade da área, dotada de infraestrutura de transportes; e impactos urbanísticos positivos, sobretudo o alargamento de ruas e a canalização dos rios da região. ${ }^{8}$

Opondo-se a essa proposta, Carlos Lacerda argumentava que seus entusiastas desconsideravam os elevados custos de reurbanização do entorno, incluindo a aquisição de terras e desapropriações, bem como a ausência de espaço para instalação de estacionamento. ${ }^{9}$ Essa oposição não se limitou a problematizar o projeto adotado pelo governo, articulando alternativas. 
Em primeiro lugar, Lacerda apresentou, em junho de 1947, um projeto de estádio a ser construído na região da restinga de Jacarepaguá, ${ }^{10}$ próximo ao ponto de encontro da Lagoa da Tijuca com o mar. Essa contraproposta resgatava um antigo projeto de cidade olímpica, elaborado em 1938 por Antonio Laviola, cujo objetivo original era criar infraestrutura esportiva no local para a realização de jogos olímpicos na capital federal. Os argumentos utilizados pelo vereador udenista ressaltavam que as terras a serem adquiridas eram mais baratas do que aquelas do Derby Clube, que a urbanização de uma região então carente de investimentos públicos a dotaria de ampla infraestrutura de transportes e que o projeto fortaleceria uma futura candidatura olímpica.

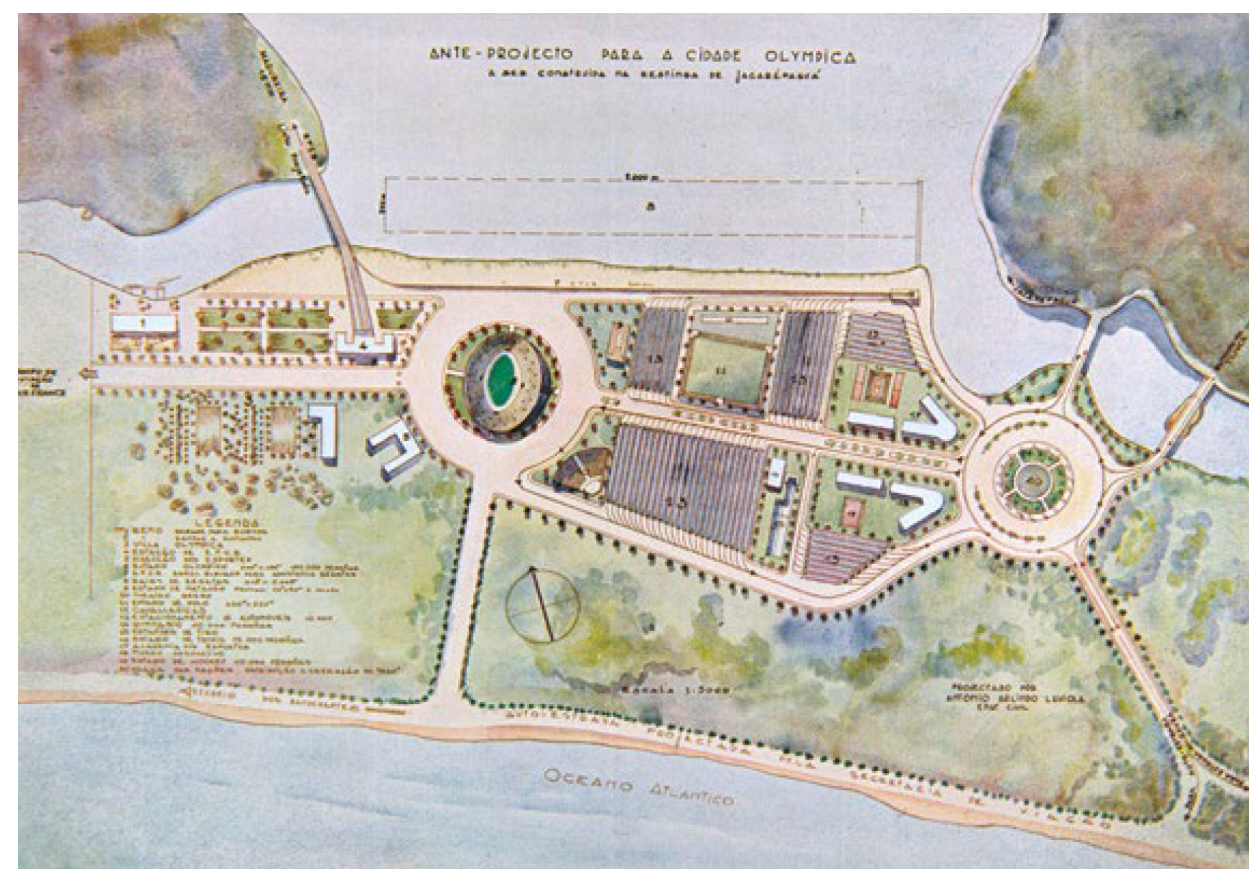

Figura 1: Anteprojeto "Cidade Olímpica", originalmente planejado por Antonio Laviola, em 1938, e utilizado por Carlos Lacerda, em 1947, para fortalecer sua contraproposta (Laviola, 1938).

O Jornal dos Sports não poupou esforços para atacar tal contraproposta. 0 principal trunfo acionado por Mario Filho e Ary Barroso foi a pesquisa de opinião realizada pelo Instituto Brasileiro de Opinião Pública e Estatística (Ibope), em agosto de 1947, de forma a intervir nos debates em curso na Câmara dos Vereadores a respeito do projeto de lei enviado pelo prefeito Mendes de Morais. Seu resultado indicava apoio popular à construção do estádio e à localização no bairro do Maracanã. A edição de 19 de agosto de 1947 do periódico trazia "números que falam da vontade do povo" em relação à "batalha do estádio". 

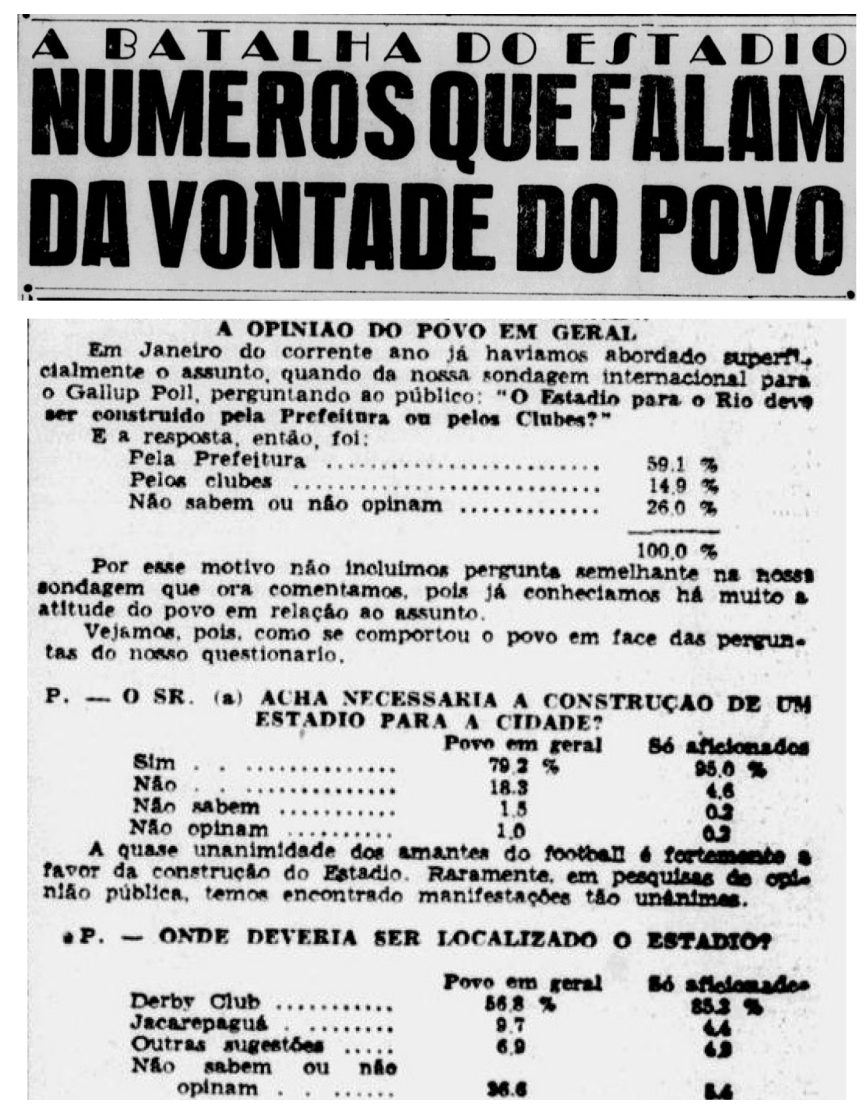

Figuras 2 e 3: Pesquisa de opinião realizada pelo Ibope e divulgada pelo Jornal dos Sports em 19 de agosto de 1947.

Além disso, Mario Filho afirmava não ser possível implementar plano tão complexo antes da Copa do Mundo, que a área da restinga de Jacarepaguá sofria com epidemias de malária e que a melhor forma de trazer as Olimpíadas para a cidade seria primeiro focar na melhor organização possível da Copa do Mundo. ${ }^{11}$ Para ele, após a Copa do Mundo, o estádio no Maracanã também poderia se transformar numa "cidade olímpica", com equipamentos esportivos ao seu redor. Vargas Neto acirrava os ataques, levantando suspeita sobre as intenções de Lacerda e Laviola, que teriam interesses imobiliários na região, ${ }^{12}$ algo negado pelo Correio da Manhã. ${ }^{13}$

Graças à aprovação da lei vinculada à viabilização do estádio nos terrenos do Derby Clube, em outubro de 1947, ${ }^{14}$ a contraproposta desapareceu das páginas dos jornais. Contudo, os meses de lentidão dos trâmites para o início das obras municipais suscitaram o anúncio de uma nova contraproposta, em março de $1948 .{ }^{15}$ Dessa vez, o Correio da Manhã apresen- 
tava o projeto do Estádio Nacional Sociedade Anônima (Ensa) como alternativa mais viável, por supostamente contar com maior rapidez de implementação pela iniciativa privada. Sua localização seria o bairro suburbano de Irajá. No entanto, a nova localização era vista como um atributo menos relevante, com os apoiadores do Ensa se limitando a argumentar que 0 estádio estaria às margens da Avenida Brasil, há menos de vinte minutos do Centro. ${ }^{16}$ Não foram encontradas outras evidências que explicassem a nova localização. ${ }^{17}$

A convergência de rumores de insucesso da iniciativa da prefeitura com o lançamento do Ensa reaqueceu os debates. 0 Jornal dos Sports contra-atacou com notícias diárias sobre 0 andamento das obras e reportagens sobre visitas de autoridades e celebridades ao local, além de fotomontagens exaltando a construção do "colosso do Derby". ${ }^{18}$

0 início efetivo das obras no Maracanã, em agosto de 1948, e a cobertura ufanista promovida pelo Jornal dos Sports refrearam o ímpeto dos arautos do Ensa, cujos anúncios publicitários e textos promocionais desapareceram em outubro do mesmo ano. Desde então, estava definida a opção pelo bairro do Maracanã.

\section{QUEM SERÁ RESPONSÁVEL PELA OBRA DO NOVO ESTÁDIO?}

principal divergência quanto à responsabilidade pela construção do estádio se con-
substanciou nas diferentes visões sobre o papel a ser desempenhado pelo Estado e pelo setor privado, com o Jornal dos Sports em favor do protagonismo do primeiro e o Correio da Manhã reivindicando o segundo.

Ainda em julho de 1946, o Correio da Manhã se antecipava ao demonstrar sua aversão à participação do Estado na construção de estádios para a Copa do Mundo. ${ }^{19}$ Em março de 1948, com o lançamento do Projeto Ensa, a definição do papel da iniciativa privada, antes uma questão secundária, passou a ocupar o centro das atenções. Fausto Matarazzo, membro da famosa família de industriais, surgia como principal incorporador do empreendimento. Isso causou críticas severas, como a de José Lins do Rêgo, cuja coluna de 7 de abril de 1948 denunciava "os homens de negócio da cidade" por "fazer do esporte um trampolim para seus interesses". Com similar tom, Mario Filho apontava a violação do decreto n 3.199, de 1941, cujo teor privilegiava a concepção amadorista de esporte, evitando a relação entre os jogos esportivos e o lucro. ${ }^{20}$

Em contrapartida, o Correio da Manhã identificava tal legislação como retrógrada, publicando pareceres de juristas que demonstravam sua inconstitucionalidade, por ferir o princípio de livre associação, e sua validade restrita à proibição de aferição de lucros por parte dos 
clubes, sem afetar a atuação de empresas no setor. ${ }^{21}$ Isso levou o Jornal dos Sports a publicar como manchete uma declaração do Conselho Nacional de Desportos (CND) reconhecendo a ilegalidade da iniciativa Ensa. ${ }^{22}$

Ainda assim, o Correio da Manhã atacaria a iniciativa governamental ao prever aumento dos custos, típico de investimentos capitaneados pelo Estado, enquanto Mario Filho responderia afirmando que, ao contrário, seriam os lucros perseguidos por empresários que encareceriam a obra, posteriormente penalizando os clubes no seu uso cotidiano do novo equipamento urbano coletivo. ${ }^{23}$

Se o campo liderado por Mario Filho e seu Jornal dos Sports defendia uma perspectiva bastante alinhada com a concepção nacional-desenvolvimentista varguista, seu rival, representado pela figura de Carlos Lacerda, adotava uma abordagem mais alinhada aos ideais liberais, predominantes até a crise mundial de 1929.24 Essas diferenças fundamentais também influenciaram os distintos formatos de viabilização financeira vislumbrados por ambos os campos.

\section{COMO VIABILIZAR FINANCEIRAMENTE O NOVO ESTÁDIO?}

pesar de defender a gestão estatal, o contexto de crise econômica mundial do ime-
diato pós-guerra não deixava muito espaço para que o campo liderado por Mario Filho reivindicasse a utilização de recursos públicos para a construção. Assim, João Lira Filho, presidente do CND, transformado em secretário municipal de Finanças, em junho de 1947, elaborou um plano de financiamento baseado na venda antecipada de 30 mil cadeiras cativas e perpétuas - o equivalente a $20 \%$ da capacidade total do novo estádio —, de maneira a suprir o orçamento previsto de 150 milhões de cruzeiros. ${ }^{25}$ Para tanto, o secretário contaria com o apoio do Jornal dos Sports e de demais aliados da imprensa na divulgação das vendas.

Mario Filho defendeu o plano, argumentando que a iniciativa faria com que o estádio fosse "de graça" e "do povo", liberando verbas públicas para outros fins. ${ }^{26}$ Lacerda, contudo, apontava para a impossibilidade de essa arrecadação cobrir os gastos necessários, pois os custos da reurbanização do entorno não estariam no orçamento anunciado. ${ }^{27}$ Lacerda e Diocesano Gomes também qualificavam os adquirentes de cadeiras cativas como "ingênuos" e de "pouca inteligência" por apostarem num projeto tão incerto. Além disso, duvidavam de haver 30 mil torcedores na cidade com condições de pagar 5 mil cruzeiros por um assento. Mais uma vez, as ações dos colunistas do Correio das Manhã contemplavam alternativas. 0 projeto Ensa propunha a venda de ações para capitalizar o empreendimento. ${ }^{28}$ 
A resposta de Mario Filho foi recrudescer a campanha pela venda de cadeiras cativas. O Jornal dos Sports passou a divulgar estatísticas dos valores arrecadados e notícias sobre a aquisição de cadeiras por celebridades, encorajando o esforço coletivo de financiamento. 0 jornal também demonstrava, mediante fotorreportagens, a evolução da construção, fortalecendo a confiança no empreendimento. ${ }^{29}$ Ao mesmo tempo, os colunistas repudiavam a tentativa de lucro por meio do esporte vinculada ao projeto Ensa. 0 avanço das obras do estádio municipal no fim de 1948 causou o abandono do projeto defendido pelo Correio da Manhã.

\section{QUAL SOCIEDADE A SER CONSTRUIIDA?}

()$^{s}$ s diferentes projetos divergiam quanto seus pressupostos, indicando a filiação a determinada concepção de sociedade. Os defensores do estádio municipal utilizaram um arcabouço simbólico de país inclusivo, onde classes e indivíduos teriam um papel no projeto de obra monumental e ícone de um novo Brasil (Moura, 1998), conforme ilustra a iconografia abaixo. A compra de cadeiras cativas por parte dos mais ricos e o empenho do prefeito e do presidente na realização do projeto, a dedicação dos operários nas obras, a promessa de ingressos mais baratos e acessíveis, a inauguração do estádio com entrada livre e a realização de cerimônia de homenagem aos operários — tudo objetivava indicar que as classes estavam unidas em torno de um projeto único, isto é, provar a "capacidade realizadora do brasileiro" por meio da construção do maior estádio do mundo.

Esse aspecto foi condensado na arquitetura interna do estádio, que, com sua forma elíptica, buscou a menor diferenciação possível entre seus assentos em termos de visualização do que ocorria no campo (Gaffney, 2008).

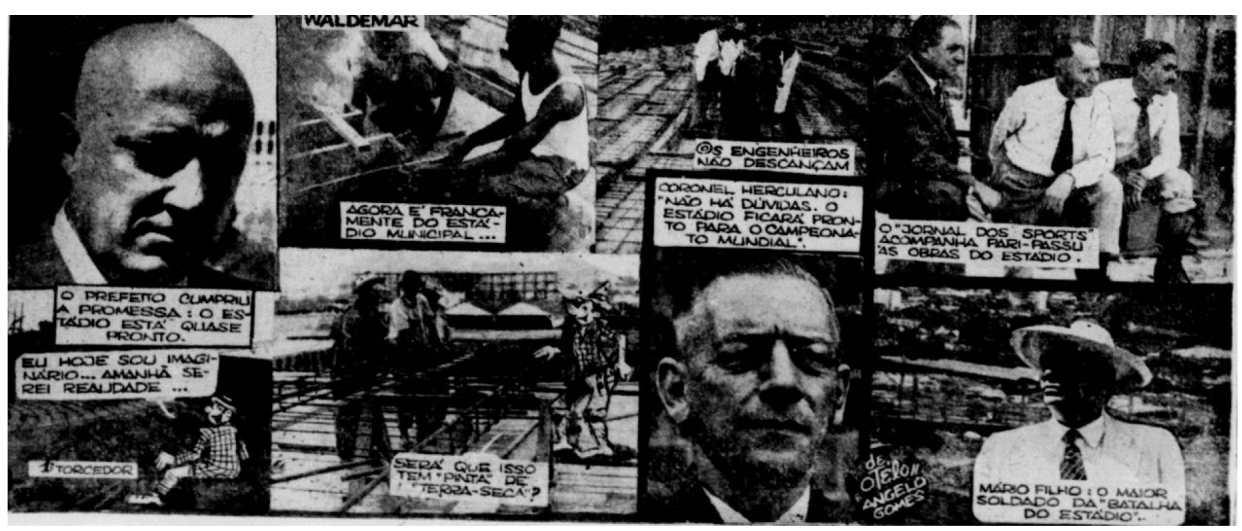

Figura 4: Fotomontagem publicada em 12 de fevereiro de 1949 pelo Jornal dos Sports, colocando lado a lado operários, o prefeito Mendes de Morais, o coronel Herculano Gomes — responsável direto pela obra — e Mario Filho. 


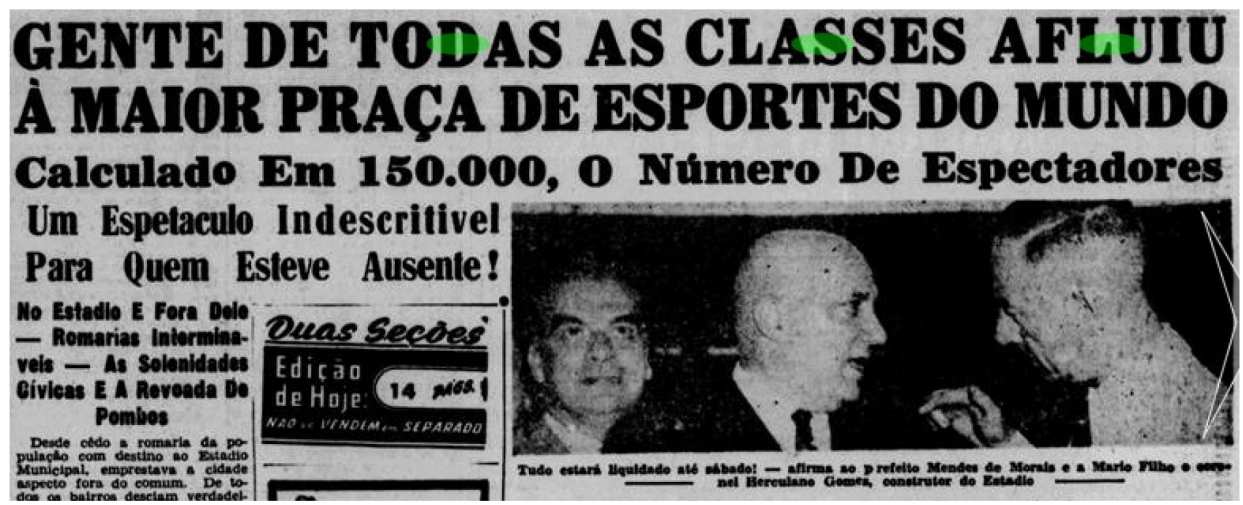

Figura 5: Manchete do Jornal dos Sports de 19 de junho de 1950, dia seguinte à inauguração do estádio municipal.

Já as contrapropostas utilizavam um discurso distinto. Ambas investiram simbolicamente na vinculação explícita entre a construção de uma nova infraestrutura esportiva para a cidade e a contribuição que ela traria à purificação da "raça brasileira". Tal vinculação estava calcada nos ideais cientificistas de branqueamento da sociedade por meio de práticas civilizatórias, como o esporte, que regenerariam a composição genética nacional maculada pela contribuição de negros e indígenas (Stepan, 2004), bastante difundidos nos meios intelectuais do país ao longo das primeiras décadas do século XX (Schwarcz, 1993).

0 anteprojeto de "cidade olímpica" para a restinga de Jacarepaguá trazia como uma de suas principais justificativas a contribuição para a "eugenia da raça", conforme afirma seu autor, Antonio Laviola: "Apaixonado como sou por todos os problemas urbanísticos e principalmente os desportivos, apresento hoje, como primeiro ensaio, um ante-projeto do que poderá e deverá ser feito, tendo sempre em mira a eugenia da raça" (1938: 89, grifo do autor). Da mesma forma, o projeto do Estádio Ensa afirmava em seu material publicitário que "todos os brasileiros que compreendem a importância do esporte para o desenvolvimento eugênico do nosso povo não negarão seu apoio aos idealizadores do Estadio E.N.S.A." ${ }^{30}$ (grifo nosso).

Por outro lado, as palavras "eugenia" e "raça" não foram encontradas nas edições do Jornal dos Sports examinadas. Isso provavelmente se deve ao fato de Mario Filho ter se filiado ao ideal culturalista freyriano (Soares, 2003), que se contrapunha aos projetos de branqueamento, exaltando a participação de negros e indígenas na miscigenada formação racial brasileira (Schwarcz, 1993). Não por acaso, Mario Filho publicara naquele momento O negro no futebol brasileiro (1947), com prefácio de Gilberto Freyre. 
Cabe, por ora, concluir que a prevalência do campo da construção do estádio municipal sobre o campo oposicionista significou muito mais do que mera escolha arquitetônica-urbanística. Para além da heterogeneidade interna aos dois campos, concepções distintas de esporte, cidade e nação estavam contidas nos respectivos projetos. A localização do Maracanã contribuiu para uma cidade de maior contato, em detrimento de uma urbe mais espraiada e segmentada. 0 estádio municipal efetivou um Estado mais proativo. 0 plano das cadeiras cativas e perpétuas fortaleceu uma visão mais coletiva, apaixonada e colaborativa do esporte em detrimento de sua submissão à lógica do lucro. Por último, o ideal freyriano de sociedade mais inclusiva e miscigenada se sobrepôs às ideias abertamente eugenistas.

Nossa leitura é a de que o caráter reconhecidamente popular do Maracanã, que décadas mais tarde justificou seu tombamento por parte do Iphan, está associado aos resultados materiais e simbólicos das disputas verificadas nesse primeiro ato.

\section{SEGUNDO ATO: DISPUTAS ACERCA DE UM VELHO ESTÁDIO PARA UMA NOVA COPA DO MUNDO (1999-2014)}

morte de Mario Filho, em 1966, fez com que o estádio oficialmente ganhasse seu
nome, a despeito de popularmente ser chamado de Estádio do Maracanã. Sua gestão permaneceu nas mãos do poder público, transferida do município para o estado do Rio de Janeiro em 1975. As cadeiras cativas, criadas para o financiamento da obra, não deixaram de existir. A ideia de criar um complexo desportivo em torno do estádio foi concretizada com a inauguração do ginásio poliesportivo Maracanãzinho, em 1954; da Escola Municipal Friedenreich, na década de 1960; do Estádio de Atletismo Célio de Barros, em 1974; e do Parque Aquático Júlio Delamare, em 1978. A grandiosidade e o caráter popular foram mantidos com a manutenção de sua capacidade de espectadores e o baixo valor dos ingressos até o fim do século $X X$, como demonstra o gráfico abaixo que apresenta a relação entre os valores dos ingressos mais baratos e do salário mínimo. 


\section{Gráfico 1 - Valores percentuais dos ingressos mais baratos do Maracanã em relação ao salário mínimo. ${ }^{31}$}

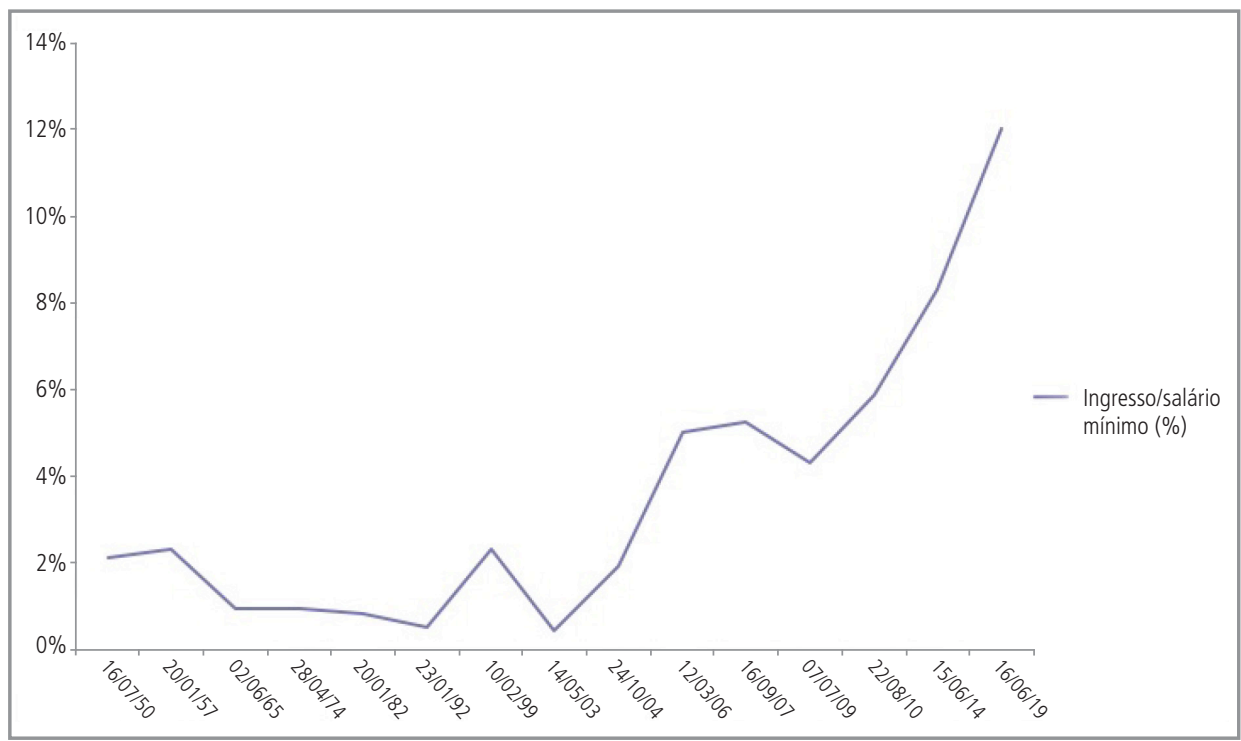

A consolidação do estádio como popular e de sua monumentalidade marcou o imaginário da cidade do Rio de Janeiro e do país, suscitando iniciativas de proteção via tombamento como patrimônio cultural no começo dos anos 1980. Naquele momento, estavam em curso algumas ações de novo tipo no campo do patrimônio cultural, com destaque para os tombamentos, $^{32}$ em 1984, do Terreiro da Casa Branca, em Salvador, e da Serra da Barriga, em Alagoas.

Desde fins dos 1970, a noção de referência cultural vinha trazendo, ainda que lentamente, um novo lugar para as culturas populares no interior do aparato das políticas (Fonseca, 1996; Calabre, 2009). Podemos apontar para um sentido de ampliação da esfera do cultural na consolidação de direitos e de formalização do reconhecimento da necessidade de políticas voltadas a setores até então desprivilegiados, expressos em ações como a criação do Centro Nacional de Referências Culturais (1975), em documentos como a Constituiçã̃o de 1988 e 0 Decreto-lei $n^{\circ} 3551$, de 2000.

A movimentação em torno do tombamento do Maracanã pelo Iphan começa em 1983, como indica a documentação apensada a seu processo, ${ }^{33}$ a pedido de Marcos Villaça, à época secretário de Cultura. É criada a série tipológica "Estádios" e solicitado às demais regionais informações sobre o tema. 0 estudo abrangeria alguns casos, desde sedes menores (divisões inferiores, amadoras etc.) até expressões espetaculares, prevalecendo o universo dos estádios maiores. 
Sobre o Maracanã, constrói-se a hipótese de que, além de sua importância histórica (Copa de 50), marca a entrada do futebol nacional em sua idade madura, citando a necessidade de reconhecer a apropriação popular do equipamento. A justificativa para o tombamento é a de qualificá-lo como símbolo maior do futebol no Brasil. Ressalta-se a possibilidade de a "proteção da rede capilar [...] salvaguardar o valor cultural da atividade do risco [...] predatório por parte da indústria cultural" ${ }^{34}$

A movimentação em torno do tombamento tem uma pausa entre 1984 e 1987, quando se afirma a necessidade de parecer técnico. A documentação volta a tratar do caso apenas em 1993, como um processo aberto e pendente. Isso coincide com o início, no Rio de Janeiro, da era do "empreendedorismo urbano" (Harvey, 1996), relacionada à ascensão do ideário neoliberal, no âmbito nacional e local, sobretudo representada pela vitória eleitoral de Cesar Maia, em 1992. Sua gestão à frente da prefeitura ignora instrumentos de planejamento consolidados, como os planos diretores, priorizando a construção dos chamados planos estratégicos, que apostam na competitividade da cidade no mercado global de atração de investimentos, em detrimento de políticas de redução de desigualdades (Arantes, Maricato, Vainer, 2000).

O plano estratégico do Rio de Janeiro, publicado em 1996, focava em ações promotoras do turismo, do entretenimento e do setor imobiliário, de maneira a contornar a decadência econômica pela qual passava a cidade após longo processo de desindustrialização e da perda de status (Sánchez, 1997). Isso envolvia, em especial, a tentativa de atração de megaeventos esportivos como elemento catalizador de uma nova dinâmica (Rio de Janeiro, 1996: 53).

Permeada por tais diretrizes, ocorre a candidatura à sede das Olimpíadas de 2004. Como parte dos preparativos para o evento, anuncia-se um projeto inédito de reforma do Maracanã que previa a extinção da geral — setor mais popular — e a redução da capacidade para 100 mil pessoas, além da construção de camarotes e de um shopping center. Embora malsucedida, a proposta reavivou discussões sobre a necessidade de tombar o Maracanã para evitar a descaracterização. Tais preocupações se mostrariam pertinentes quando a Fifa acertou com autoridades públicas locais a realização do primeiro campeonato mundial de clubes no estádio, em 2000, e solicitou reformas similares às da candidatura olímpica de 2004. 


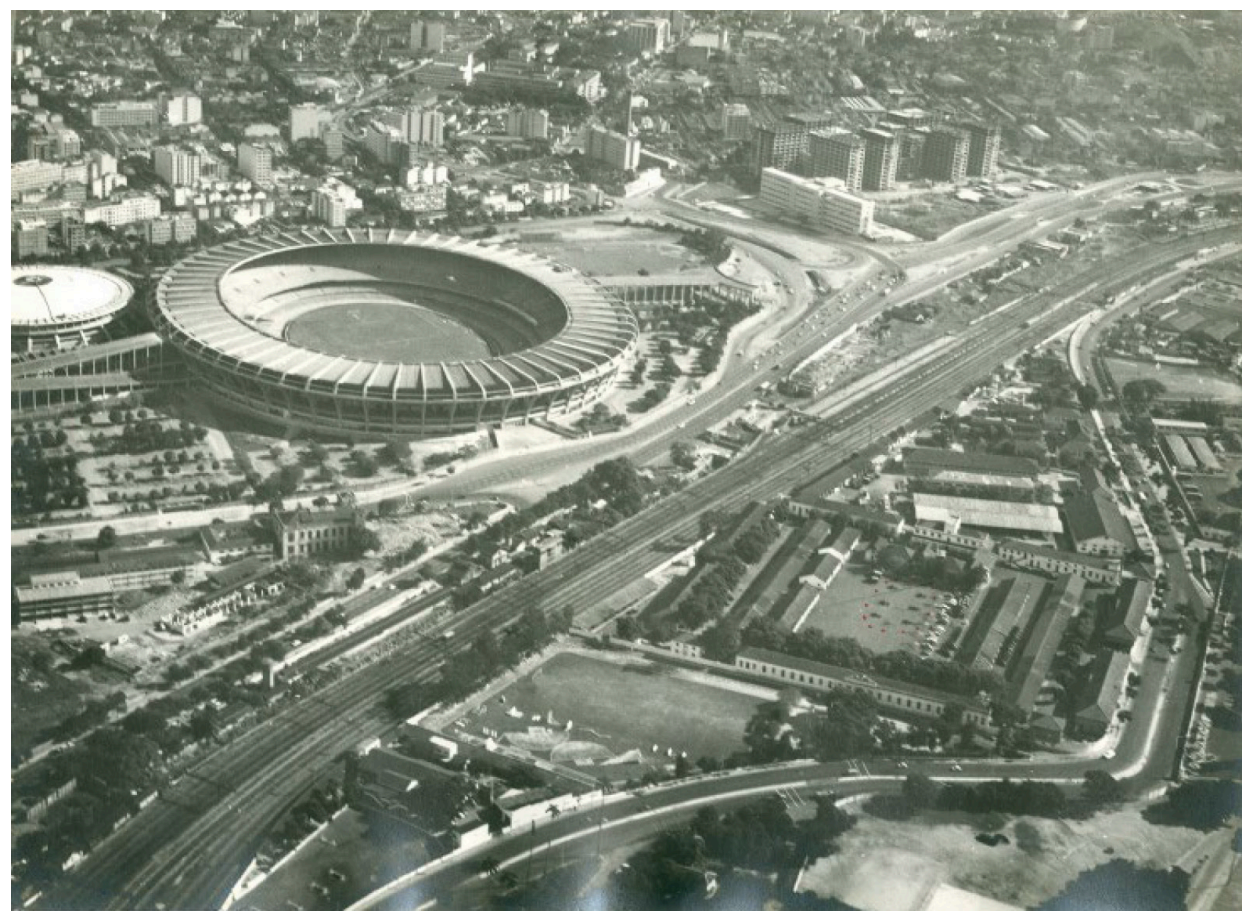

Figura 6 - Vista aérea do Estádio Mário Filho e cercanias, década de 1970, acervo do 3 E.R.A., Base Aérea de Campo dos Afonsos, cedida pelo $3 \% 8^{\circ}$ Grupo de Aviação. ${ }^{35}$

Em fevereiro de 1997, o tema foi retomado pelo Iphan, em memorando citando o "iminente risco de descaracterização", ${ }^{36}$ sugerindo a aplicação da dispensa de instrução formal. A conclusão dos técnicos do Iphan foi que havia requisitos para o tombamento, que deveria seguir para apreciação do Conselho Consultivo do Patrimônio Cultural. 0 exame argumentava que a proposta original do estádio previa a construção de um complexo desportivo, indicando que o objeto do tombamento deveria incorporar os prédios do complexo. 0 parecer afirmava que o bem estava "diretamente relacionado a fatos históricos e etnográficos notáveis", ressaltando as "particularidades audaciosas para sua época". 

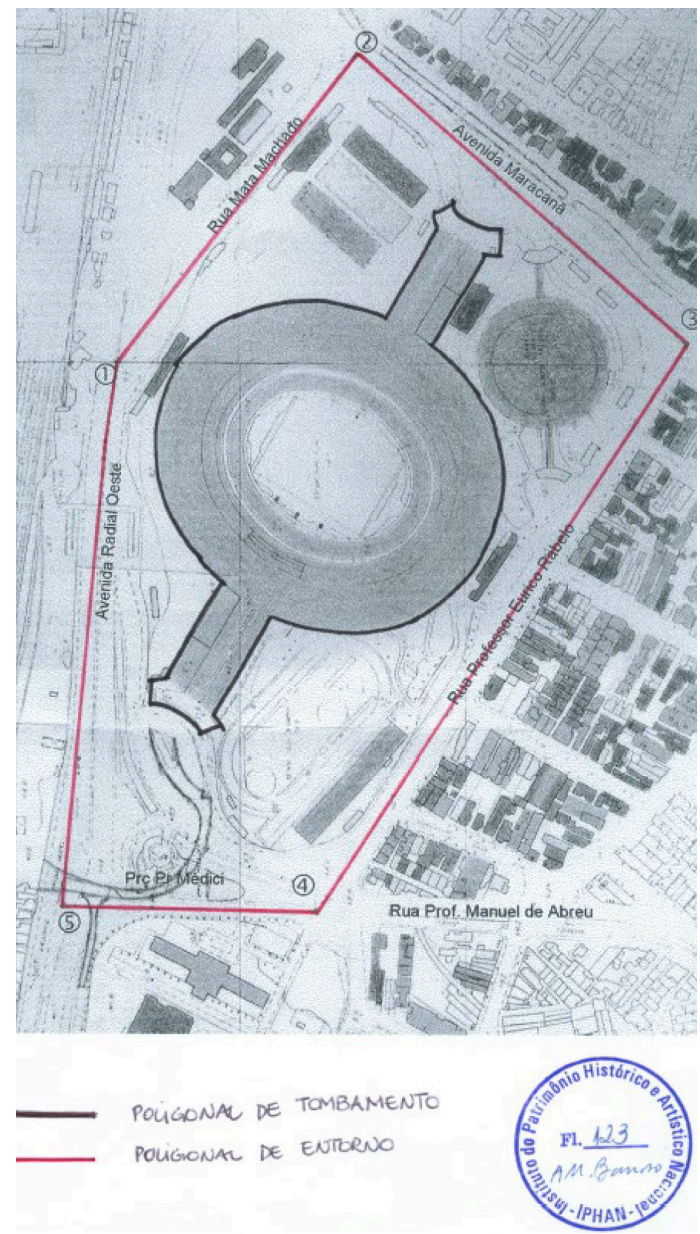

Figura 7 - Desenho da poligonal anexado ao Memorando no 130/97, de 4 de fevereiro de 1997. ${ }^{37}$

Ainda em fevereiro de 1997, o Iphan informou à Superintendência de Esportes do Estado do Rio de Janeiro (Suderj), à Secretaria de Planejamento do Estado do Rio de Janeiro e ao Comitê Olímpico Brasileiro (COB) sobre o processo de tombamento aberto. Solicitou-se às instituições o encaminhamento, para a análise do Iphan, de projetos que poderiam ser realizados. Apenas em 2000 o tombamento foi novamente analisado por parte dos técnicos do Iphan.

Em fevereiro de 2000, um laudo ${ }^{38}$ chamou a atenção para duas questões: inserção de cadeiras nas arquibancadas e redução da capacidade do estádio de 180 para 110 mil pagantes. Essas alterações se somaram a outras de menor impacto, como construção de camarotes e de 
rampa de acesso. Embora receoso, o exame concluiu que não havia riscos de descaracterização até o momento. 0 Conselho Consultivo foi informado da obra em andamento, da análise técnica e da recomendação de inscrição também no Livro do Tombo Arqueológico, Etnográfico e Paisagístico. ${ }^{39}$

Coube ao conselheiro Nestor Goulart Reis Filho a relatoria do caso. 0 parecer ${ }^{40}$ do conseIheiro reiterava a "extraordinária monumentalidade do estádio Mário Filho e seu valor simbólico", apontando ainda outra dimensão até então não abordada, isto é, a relação da cidadania com o patrimônio cultural.

Na 21a Reunião do Conselho Consultivo do Patrimônio Cultural, em 13 de abril de 2000, foi decidida a aprovação do tombamento e a delimitação do entorno do Estádio do Maracanã. ${ }^{41}$ A Ata ${ }^{42}$ demonstrou o entendimento do caráter simbólico da reunião de setores da sociedade no estádio, destacando a apropriação do bem pelas camadas populares que dele se tornaram marca, conforme demonstra a fala do Relator: "Em geral, as obras monumentais são afirmações de poder sobre o povo. Neste caso, ocorre o contrário. 0 Maracanã tem a monumentalidade da massa que o utiliza, a qual representa". As reformas em andamento foram pontuadas, quando se reafirmou o entendimento de manutenção das características populares: "o tombamento do Maracanã não pode excluir a geral. [...] o fundamental do Maracanã não é a obra de arquitetura, mas o cenário desse grande congraçamento."

Marcos Vilaça, presente como conselheiro, lembrou que teve a felicidade de participar da aprovação do tombamento do Terreiro da Casa Branca, na Bahia; do Açude do Cedro, no Ceará; da Avenida Modelo, mas que "faltava este Maracanã. [...] Eu não conheço melhor qualificação para esse local de apoteose democrática que a expressão encontrada pelo Conselheiro Nestor Goulart: monumentalidade da massa".

\section{MEGAEVENTOS E REFORMAS, A CIDADE DO PENSAMENTO ÚNICO: NARRATIVAS DE OBSOLESCÊNCIA E DESTRUIÇÃO DO COMPLEXO ESPORTIVO}

pesar do tombamento afirmado pelo Iphan, novos acontecimentos colocariam em
risco, mais uma vez, o Maracanã. Em 2003, a prefeitura, em parceria com o COB, garantiu a organização dos Jogos Pan-Americanos de 2007, como estratégia para atrair as Olimpíadas. De fato, ainda no fim da mesma década, o Brasil foi confirmado como sede da Copa do Mundo de 2014 e das Olimpíadas de 2016.43 A preparação para os três eventos aumentou a pressão por reformas no Maracanã. 0 estádio teria sua capacidade novamente reduzida, incluindo a extinção da geral, numa primeira reforma para os jogos Pan-Americanos. 
Em seguida, uma nova reforma para a Copa do Mundo ampliaria a área destinada aos camarotes, reduzindo mais uma vez a capacidade total, para 78 mil espectadores, reivindicando a destruição interna, com a justificativa de adaptar o estádio às exigências da Fifa.

Por último, mas não menos importante, o contrato de concessão do complexo para a gestão privada, firmado em 2013, previa a destruição do Parque Aquático Julio Delamare, do Estádio Célio de Barros, da Escola Municipal Friedenreich e do antigo Museu do Índio para dar lugar a estacionamentos, cinemas e lojas. Tais ações não foram efetivadas graças à resistência popular e à atuação de órgãos jurídicos e de defesa do patrimônio, conforme será visto a seguir.

0 tombamento do estádio e de seu entorno foi tensionado. É possível, mesmo se nos ativermos à documentação institucional, ler os desacordos internos frente à reforma. A documentação apensada ao processo de tombamento dá conta do imbróglio jurídico e institucional, evidenciando três atores: a Defensoria Pública da União, a Superintendência Regional e o Conselho Consultivo do Patrimônio Cultural.

A querela teve início em abril de 2013, quando a Superintendência do Iphan no Rio de Janeiro, por meio de ofício ${ }^{44}$ à Secretaria da Casa Civil do Estado do Rio de Janeiro, informou seu posicionamento quanto às intervenções no entorno do Maracanã, recomendando a manutenção do Maracanãzinho e do prédio do Museu do Índio, mas anuindo quanto à demolição dos estádios Célio de Barros e Julio Delamare, bem como da Escola Municipal.

Em abril de 2013, o defensor público federal André Silva Ordacgy informou à Superintendência do Iphan que discordou da autorização para a destruição parcial e/ou integral dos parques esportivos. Em ofício, ${ }^{45}$ solicitou o impedimento de qualquer atividade de demolição dos bens e o tombamento provisório.

A Superintendência do Iphan no Rio de Janeiro, em maio de 2013, esclareceu que um parecer técnico em construção tinha por proposta a falta de interesse federal nos bens citados por "estarem destituídos dos requisitos necessários para integrarem o patrimônio cultural nacional, em suas diferentes vertentes". ${ }^{46}$ Um segundo ponto destacava que, por ocasião do tombamento do Maracanã, em 2000, o Iphan já analisara a região, verificando que a justificativa para o tombamento do conjunto não se justificava. 0 defensor público federal discordou dos argumentos e solicitou toda a documentação para análise.

A arquiteta Claudia Girão Barroso, do Iphan, elaborou um parecer ${ }^{47}$ sobre o pedido de tombamento dos estádios. Tal parecer afirmava que o processo de tombamento fazia referência ao complexo esportivo e entendia o complexo como componente do Estádio do Maracanã, citando a representação da poligonal de tombamento (ver figura 7). 
André Ordacgy, ${ }^{48}$ em relatório, apontou para a conduta "injustificável da Superintendência do Iphan-RJ", uma vez que, sem acionamento do governo do estado do Rio de Janeiro, emitiu autorização de demolição dos bens que estavam dentro do entorno do Estádio do Maracanã, descumprindo a Portaria Iphan n 420/2010. Outro destaque foi o fato de a Superintendência não poder, unilateralmente, se sobrepor à decisão do Conselho Consultivo do Patrimônio Cultural.

O relatório ainda ia de encontro às justificativas dadas pelo governo do estado, baseadas em estudo de viabilidade técnica da empresa IMX, que apresentou o Estádio como complexo de entretenimento, afastando-se da característica de complexo desportivo. Segundo o defensor, havia "inverdades" no estudo entregue pela IMX, uma vez que apontava ociosidade dos estádios. 0 ofício do Conselho Regional de Engenharia e Agronomia do Rio de Janeiro (Crea-RJ), se contrapunha ao entendimento da empresa Steer Davies Gleave, também contratada pelo governo do estado, que afirmava ser necessária a derrubada dos estádios visando ao escoamento do público. 0 Crea-RJ afirmou categoricamente que os estádios não impediriam a livre circulação de pessoas durante a Copa do Mundo de 2014.

Antes do debate sobre a demolição do Célio de Barros e do Julio Delamare, outra questão se colocou como ilustrativa das tensões em jogo nas mudanças radicais no Estádio do Maracanã. Em agosto de 2011, ocorreu a 68 Reunião do Conselho Consultivo do Patrimônio Cultural, tendo em pauta o tema "Revitalização do Estádio Mário Filho". ${ }^{9}$ Dado o caráter público da intervenção em andamento, iniciou-se o debate do tema com a exposição do presidente da Empresa de Obras Públicas do Estado do Rio de Janeiro (Emop), Ícaro Moreno Júnior.

Ícaro expôs a necessidade de preparação para a Copa, seguindo exigências do caderno de encargos da Fifa, e afirmou haver um projeto apresentado ao Iphan e aprovado pelo superintendente Carlos Fernando Souza Leão de Andrade, além de apontar a deterioração das estruturas como justificativa para a demolição da marquise e da arquibancada.

0 presidente do conselho iniciou o debate lembrando que havia uma ação de questionamento das intervenções por parte do Ministério Público, na Justiça Federal. 0 relato da reunião indicou unanimidade entre os conselheiros sobre o erro na aprovação da demolição. Entre as muitas falas, destacamos a de Ítalo Campofiorito:

0 valor atribuído ao Maracanã para o tombamento é etnográfico, no sentido em que o Decreto-lei 25 dá à palavra. [...] Ele (Carlos Fernando de Souza Leão Andrade) poderia ter procurado 0 Conselho, e vindo aqui discutir conosco e dizer: "Acho que o Maracanã deve ser usado, mas ele só poderá ser usado se for modificado o seu estatuto, o tombamento não vai ser respeitado, 0 que está escrito na lei não vai ser obedecido, ele vai mudar fisicamente." 
Já Eugênio de Ávila Lins lamentou que tenham feito o projeto, e o aprovado, "antes de ter um diagnóstico real do objeto com que estavam trabalhando". Ele lembrou que boa parte do patrimônio moderno brasileiro está em situação similar à do Maracanã: "Vamos continuar tombando esse patrimônio moderno para depois ser modificado? Fica também o exemplo extremamente lastimável da Fonte Nova". ${ }^{50}$

Ulpiano Bezerra de Menezes destacou "dois gravíssimos desvios de conceito, escandalosamente inaceitáveis, principalmente por quem teria a responsabilidade de ter um encaminhamento de outra natureza". Liberal de Castro ressaltou a importância arquitetônica do estádio e mencionou diversas obras, como a do Mineirão, em Belo Horizonte, e a do Castelão, em Fortaleza, com indignação: "É triste ver a destruição gratuita de documentos que retratam ou retrataram materialmente a História da Arquitetura Moderna Brasileira." ${ }^{51}$ Já Nestor Goulart Reis expôs sua indignação:

Eu me sinto profundamente revoltado pelo modo como meu parecer foi utilizado, com má fé, para inverter o sentido de tudo aquilo que escrevi. [...] Não conheço obra de demolição em edifício tombado; nunca vi. Só conheço obra de restauração e conservação, aqui e no mundo inteiro. Destruir obras tombadas é crime [...]. Demolir a marquise, demolir as arquibancadas é demolir o Maracanã. [...] então, creio é uma questão de princípio: se o Maracanã pode ser demolido, em metade dele, pelo lado interior, todos os edifícios tombados podem ser demolidos neste país e a legislação não se sustenta mais [...]. Arquitetura, Engenheiro (dirigindo-se ao Secretário de Estado do Rio de Janeiro), não é fachada. Se conservarmos o lado de fora e destruirmos tudo dentro, o edifício não foi conservado. [...] Também, Engenheiro, não é verdade que não se possa restaurar as estruturas. [...] Quem vai assumir esta responsabilidade é quem tem que tomar as decisões políticas. Este Conselho não pode ficar no meio dessa situação. [...] Não é o Presidente desta casa que destomba.

Não temos informações sobre o desenrolar do caso dentro do Iphan ou no âmbito da Justiça Federal. A Ata registra a seguinte resolução:

Conquanto os Conselheiros reconheçam não caber ao Conselho Consultivo deliberar sobre intervenções em bens tombados, diante das falas dos membros do Conselho quanto à motivação da posição assumida pela Superintendência do Iphan no Rio de Janeiro, sugeriu o não encaminhamento de qualquer proposta tendente ao cancelamento do tombamento daquele Estádio à instância competente, registrando-se na ata daquela reunião uma posição de censura à Superintendência pelos fundamentos utilizados em seu parecer. Os membros do Conselho acolheram a proposta por unanimidade. 


\section{CONCLUSÕES}

$\mathrm{D}$ ividimos a batalha do estádio em dois atos. 0 primeiro deles disse respeito ao momento em que uma concepção mais inclusiva de esporte, estádio, cidade e país conseguiu se sobrepor à visão que propunha um projeto em local apartado da cidade, com administração privada. 0 resultado das disputas nesse primeiro ato imprimiu um caráter inegavelmente popular e público ao Maracanã, que se manteve ao longo de décadas. Em fins do século XX, iniciou-se o segundo ato, quando esse caráter voltou a ser contestado e disputado na medida em que a era do planejamento estratégico e de seus megaeventos teve início.

A reação a essa contestação foi a iniciativa de tombamento, que objetivava proteger o interesse público frente à nova investida contra o Maracanã monumental e popular. Embora formalmente tombado, as pressões por transformações de ordem arquitetônica, de gestão e simbólicas foram recrudescidas, levando à descaracterização do bem e à destruição de seu caráter popular e público. A administração recente do estádio, por meio de Parceria Público-Privada (PPP), se demonstrou desastrosa com a transformação da pista de atletismo do estádio Célio de Barros em estacionamento e com a prática de preços proibitivos que resultou no afastamento do símbolo maior do estádio: os geraldinos.

A resistência à última investida de apropriação do bem público por interesses privados e empresariais, porém, logrou algum êxito, conseguindo a preservação do Julio Delamare, da Friedenreich e do prédio do Museu do Índio — vitórias que precisam ser narradas numa próxima ocasião. Atualmente, observamos a devolução, ainda que aparentemente temporária, do estádio para o governo do estado e o fim da PPP que administra o complexo. ${ }^{52}$ Será o início de um novo (terceiro) ato da batalha do estádio?

\section{NOTAS}

1 Embora as disputas acerca do Maracanã se estendam ao longo da segunda metade do século XX, os recortes aqui analisados são aqueles cruciais para o entendimento dos principais projetos para o estádio.

2 Pelo mesmo motivo, as Olimpíadas de Helsinque também foram reprogramadas: de 1940 para 1952.

3 Uma leitura sobre as transformações nessa primeira metade de século pode ser lida em Sevcenko (1998).

4 Cumpre destacar a opção de não apresentar, dado o limite de um artigo, o debate anterior sobre o projeto para o campus da Universidade do Brasil e seus desdobramentos na construção do Estádio Nacional. Sobre 0 assunto, ver Comas (2011).

5 Jornais como 0 Globo, A Manhã e Jornal do Brasil também dedicaram espaço, mas sem o mesmo destaque.

6 Ver, por exemplo, a coluna de Mario Filho, na edição de 7 de maio de 1947, do Jornal dos Sports. 
7 Ver Jornal dos Sports de 9 de agosto de 1947.

8 Ver Jornal dos Sports de 24 de junho de 1947 e 7 de março de 1948.

9 Ver, por exemplo, Correio da Manhã de 20 de junho de 1947.

10 Ver Correio da Manhã de 24 de junho de 1947.

11 Ver artigo de Mario Filho, de 19 de junho de 1947, no Jornal dos Sports.

12 Ver coluna de Vargas Netto, de 17 de setembro de 1947, no Jornal dos Sports.

13 Ver carta de Antônio Laviola, em resposta a Ary Barroso, publicada na coluna de Carlos Lacerda do dia28 de agosto de 1947.

14 Ver as edições de 30 de outubro e $1^{\circ}$ de novembro de 1947 no Jornal dos Sports.

15 Ver Correio da Manhã de 18 de março de 1948.

16 Ver anúncio publicitário do Estádio Ensa publicado no Jornal dos Sports em 27 de junho de 1948.

17 A identificação das razões e dos atores que influenciaram a escolha dos locais propostos se ateve ao conteúdo disponível nas fontes consultadas. Sugerimos, contudo, que novas pesquisas acerca do tema explorem mais detalhadamente esse aspecto.

18 Ver, por exemplo, edição do Jornal dos Sports de 13 de agosto de 1948.

19 Ver edição de 28 de julho de 1946 do Correio da Manhã.

20 Ver sua coluna em Jornal dos Sports de 23 de março de 1948.

21 Ver artigo intitulado "Um parecer sobre o estádio nacional", na seção de esportes de 4 de abril de 1948.

22 Ver Jornal dos Sports de 17 de abril de 1948.

23 Ver Jornal dos Sports de 10 de abril de 1948.

24 Para mais detalhes sobre o nacional-desenvolvimentismo e sua contraposição às visões liberais, ver Bastos (2006).

25 Ver edição de 25 de maio de 1947 do Jornal dos Sports.

26 Ver Jornal dos Sports de 13 de agosto de 1947.

27 Ver, por exemplo, as colunas de Lacerda nos dias 11 e 12 de setembro de 1947.

28 Ver Correio da Manhã de 18 de março de 1948.

29 Ver, por exemplo, Jornal dos Sports de 19 de setembro de 1948.

30 Anúncio no Jornal dos Sports de 27 de junho de 1948.

310 cálculo considera a razão entre os valores de ingressos mais baratos disponíveis para venda e o valor do salário mínimo nas seguintes datas: 16/7/1950, Brasil x Uruguai; 20/1/1957, Flamengo x Honved; 2/6/1965, Brasil x Bélgica; 28/4/1974, Brasil x Grécia; 20/1/1982, Flamengo x São Paulo; 23/1/1992, Flamengo x Vasco e Corinthians x Palmeiras; 10/2/1999, Botafogo x Flamengo; 14/5/2003, Flamengo x Vitória; 24/10/2004, Flamengo x Vasco; 12/3/2006, Fluminense x Botafogo; 16/9/2007, Flamengo x Vasco; 7/7/2009, Fluminense x Botafogo; 22/08/2010, Vasco x Fluminense; 15/6/2014, Argentina x Bósnia; 16/6/2019, Paraguai x Catar. 
32 Dado o limite de espaço, não é possível aprofundarmos o debate sobre o instrumento jurídico do tombamento. 0 instrumento foi criado pelo Decreto-Lei $n^{\circ} 25$, de 1937, que define o Patrimônio cultural como de interesse público, sobrepondo-se ao interesse privado, além de criar o Conselho Consultivo do Patrimônio Cultural, colegiado que deve julgar os pedidos de reconhecimento de bens como patrimônio cultural. Ver Rabello (2009).

33 Processo de Tombamento nº 1.094-T-83, Estádio Mário Filho (Estádio do Maracanã), no Município do Rio de Janeiro, Estado do Rio de Janeiro.

34 Ofício de 4 de novembro de 1983.

35 Processo de Tombamento no 1.094-T-83, v. 1, p. 124.

36 Memo DEPRTO/RJ n 130/97, 4 de fevereiro de 1997.

37 Processo de Tombamento nº 1.094-T-83, v. 1, p.130.

38 Laudo 004/2000, 3 de fevereiro de 2000.

39 Memorando $n^{\circ}$ 118/00, 22 de fevereiro de 2000.

40 Processo de Tombamento no $1.094-T-83$, v. 2, p. 5.

41 A homologação se deu pela Portaria $n^{\circ} 380$, de 26 de setembro de 2000, assinada pelo ministro da Cultura.

42 Ata da $21^{\text {a }}$ Reunião do Conselho Consultivo do Patrimônio Cultural.

43 Além da Copa do Mundo de 2014 e das Olimpíadas de 2016, podemos entender na chave dos megaeventos os Jogos Pan-Americanos de 2007, os Jogos Mundiais Militares de 2011, a Jornada Mundial da Juventude de 2013. Para um aprofundamento sobre as tensões na realização desses eventos e o envolvimento de diferentes órgãos, ver Damo e Oliven (2013); Santos Junior, Gaffney e Ribeiro (2016).

44 Ofício GAB/Iphan-RJ nº 00471/13, de 25 de abril de 2013.

45 Ofício nº NDPU-RJ/019/2013/GAB/1 DHT/ASO, de 30 de abril de 2013.

46 Ofício/GAB/lphan/RJ n 00544/2013, de 10 de maio de 2013.

47 Parecer $n^{\circ}$ 159/2013/Cetec/lphan-RJ

48 Relatório e conclusões da Defensoria Pública da União - Referência: Tombamento federal do Estádio de Atletismo Célio de Barros e do Parque Aquático Júlio Delamare, Processo de Tombamento n 1.094-T-83, v.3, p. 113-133.

49 Ata da $68^{a}$ Reunião do Conselho Consultivo do Patrimônio Cultural — Iphan.

50 Estádio Otávio Mangabeira, conhecido como Fonte Nova, em Salvador, implodido em 29 de agosto de 2010, para construção do novo Itaipava Arena Fonte Nova.

51 Por limitações do artigo, não podemos avançar na análise de outros estádios impactados pela preparação para a Copa do Mundo de 2014. Para mais considerações sobre o tema, ver Mascarenhas (2019).

52 "Governo do Rio rescinde contrato de concessão do Maracanã", O Globo, 18 de março de 2019. 


\section{REFERÊNCIAS BIBLIOGRÁFICAS}

AGGIO, Alberto; BARBOSA, Aguinaldo; COELHO, Hercídia. Política e sociedade no Brasil (1930-1964). São Paulo: Annablume, 2002

ALVES, José Eustáquio D.; BRUNO, Miguel. População e Crescimento Econômico de Longo Prazo no Brasil: como aproveitar a janela de oportunidade demográfica? XV Encontro Nacional de Estudos Populacionais, Caxambu, MG, Brasil, 2002.

ARANTES, Otília; MARICATO, Ermínia; VAINER, Carlos. A cidade do pensamento único: desmanchando consensos. Petrópolis: Vozes, 2000.

BASTOS, Pedro Paulo Zaluth. A construção do nacional-desenvolvimentismo de Getúlio Vargas e a dinâmica de interação entre Estado e mercado nos setores de base. Revista Economia, v. 7, n. 4 (selecta), dez. 2006.

CALABRE, Lia. Políticas culturais no Brasil: dos anos 1930 ao século XXI. Rio de Janeiro: FGV, 2009.

COMAS, Carlos Eduardo. Niemeyer e o estádio do Maracanã. Arqtexto (Porto Alegre), v. 17, 2011.

DAMO, Arlei Sander; OLIVEN, Rubem George. O Brasil no horizonte dos megaeventos esportivos de 2014 e 2016: sua cara, seus sócios e seus negócios. Horizontes Antropológicos (Porto Alegre), v. 40, 2013.

FONSECA, Maria Cecília Londres. Da modernização à participação: a política federal de preservação nos anos 70 e 80. Revista do Patrimônio Histórico e Artístico Nacional (Brasília), n. 24, 1996.

FRANZINI, Fabio. Da expectativa fremente à decepção amarga. Revista de História (São Paulo), n. 163, 2003.

GAFFNEY, Christopher Thommas. Temples of the earthbound gods: stadiums in the cultural landscapes of Rio de Janeiro and Buenos Aires. Austin: University of Texas Press, 2008.

HARVEY, David. Do gerenciamento ao empresariamento: a transformação da administração urbana no capitalismo tardio. Espaço \& Debates (São Paulo), n. 39, 1996.

LAVIOLA, Antonio. Ante-projeto para a cidade olímpica (a ser construída na restinga de Jacarepaguá). Revista Municipal de engenharia, v. 5, n. 6, 1938.

MASCARENHAS, Gilmar. A goleada do capital sobre a memória coletiva: o "bota-abaixo" no patrimônio esportivo. In: DOMINGUES, João; TELLES, Mário Ferreira de Pragmácio (org.). Memória, patrimônio cultural e a questão urbana no Rio de Janeiro: contradições, conflitos e desafios. Rio de Janeiro: Letra Capital, 2019.

MELO, Erick Silva Om-ena de. Percepções urbanas em jogo: os impactos da Copa do Mundo de 1950 à luz da imprensa carioca. Rio de Janeiro: Pnap/FBN, 2011.

MOURA, Gisella de Araujo. O Rio corre para o Maracanã. Rio de Janeiro: FGV, 1998.

PERREIRA, Leonardo Affonso de Miranda. Footballmania: uma história social do futebol no Rio de Janeiro. Rio de Janeiro: Nova Fronteira, 2000.

RABELLO, Sonia. O Estado na preservação dos bens culturais: o tombamento. Rio de Janeiro: Iphan, 2009.

RIO DE JANEIRO. Plano estratégico da Cidade do Rio de Janeiro. Rio de Janeiro: Rio sempre Rio, 1996.

RODRIGUES FILHO, Mario. O negro no futebol brasileiro. Rio de Janeiro: Mauad, 2003.

SÁNCHEZ, Fernanda. Cidade espetáculo: política, planejamento e city marketing. Curitiba: Palavra, 1997. 
SANTOS JUNIOR, Orlando Alves dos; GAFFNEY, Christopher; RIBEIRO, Luiz Cesar de Queiroz (org.). Brasil: os impactos da Copa do Mundo 2014 e das Olimpíadas 2016. Rio de Janeiro: E-papers, 2015.

SCHWARCS, Lilia Moritiz. O espetáculo das raças: instituições e questão racial no Brasil (1870-1930). São Paulo: Companhia das Letras, 1993.

SEVCENKO, Nicolau. A capital irradiante: técnica, ritmos e ritos do Rio. In. NOVAIS, Fernando A.; SEVCENKO, Nicolau (org.). História da vida privada no Brasil: volume 3. São Paulo: Companhia das Letras, 1998.

SOARES, A. J. G. Futebol brasileiro e sociedade: a interpretação culturalista de Gilberto Freyre. In: ALABARCES, Pablo (org.). Futbologías: fútbol, identidade y violencia en América Latina. Buenos Aires: CLACSO, 2003, p. $145-162$.

SOUZA, Denaldo Alchorne de. O Brasil entra em campo: construções e reconstruções da identidade nacional (1930-1947). São Paulo: Annablume, 2008.

STEPAN, N. Eugenia no Brasil. 1917-1940. In: HOCHMANN, G.; ARMUS, D. (orgs.). Cuidar, controlar, curar: ensaios históricos sobre saúde e doença na América Latina e Caribe. Rio de Janeiro: Fiocruz, 2004, p. 331-391. 